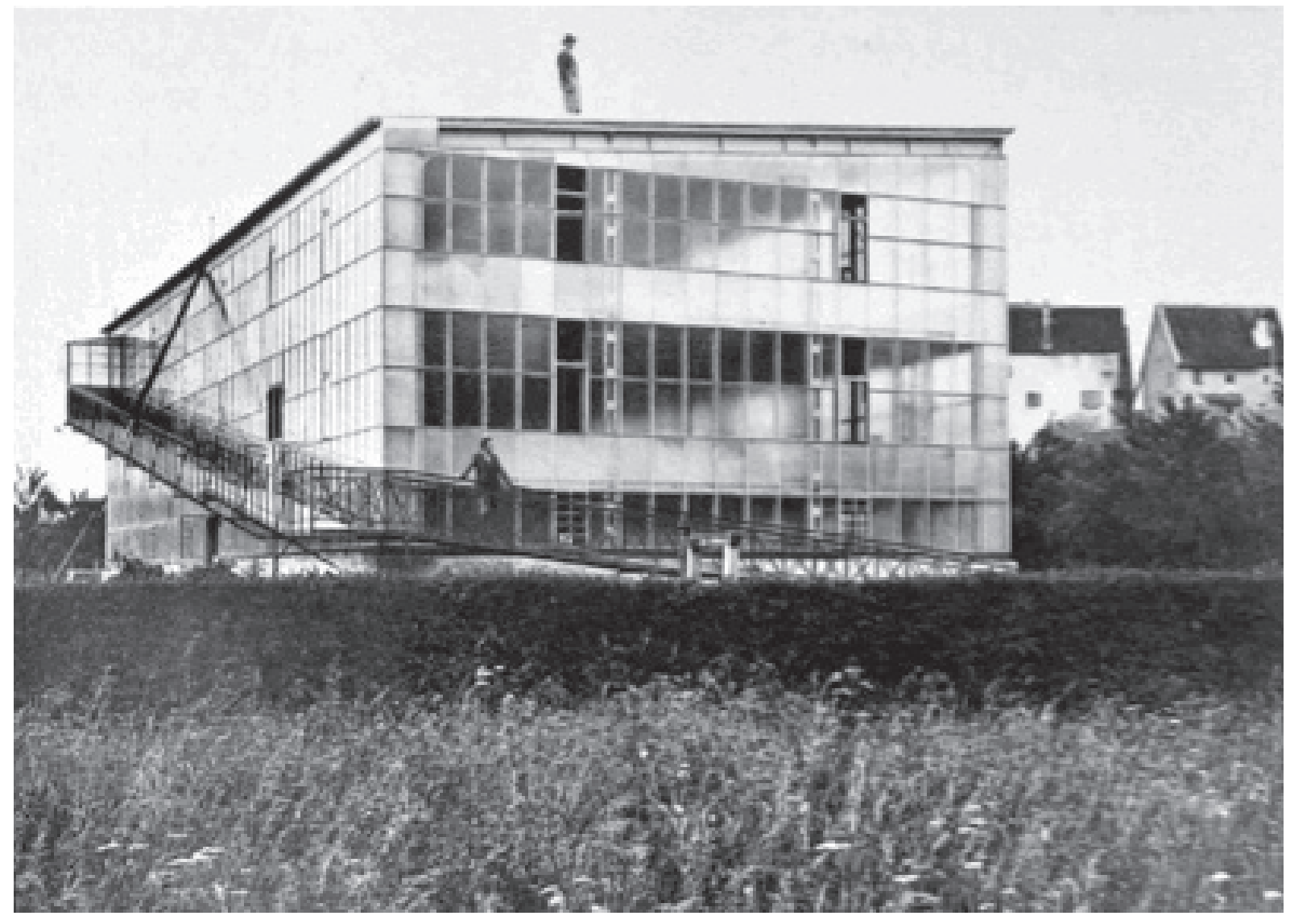




\section{Steiff Factory, 1903 Historia de una pionera Blanca Lleó}

Hace un siglo el progreso en todas sus manifestaciones suscitaba un entusiasmo colectivo. Por entonces, la arquitectura de vidrio y acero emocionaba como símbolo y expresión de las más altas aspiraciones de libertad material y espiritual. Con el transcurrir del tiempo se ha ido trastocando nuestra conciencia y nuestra sensibilidad, y hoy apesadumbrados nos sentimos culpables de haber incentivado un incalculable derroche energético causado por el uso descontrolado de aquellos deslumbrantes materiales. "El hombre es un dios cuando sueña y un mendigo cuando reflexiona", son sabias palabras de Hölderlin cuando anhelante rememora otros tiempos y nos muestra que aún no sabemos el pasado que nos espera. Con ese mismo afán, este artículo nos traslada a los fulgurantes inicios de la arquitectura de cristal para desvelar una arquitectura insólita y pionera realizada en 1903: la Steiff Factory.

PALABRAS CLAVE

Arquitectura, Steiff, pionera, cristal, teddybear

KEYWORDS

Architecture, Steiff, Pioneer, Glass, Teddybear

“¿Cuál fue el primer edificio moderno?” se preguntaban, en 1980, Alison y Peter Smithson.

La respuesta había quedado implícita años atrás en su álbum de familia titulado "The Heroic Period of Modern Architecture (1910-1929)"'; aquella selección de obras germinales de la arquitectura moderna, realizadas por los jóvenes arquitectos entre 1955 y 1956, se abría de forma intencionada con siete fotografías de la fábrica Fagus de Walter Gropius y Adolf Meyer.

Todo origen es mítico y todos los mitos son creaciones humanas. El movimiento moderno no es una excepción y su inicio, hace ya más de un siglo, fue tan mítico como el nacimiento de Venus. Del mismo modo que el sublime cuadro de Botticelli plasmó el advenimiento de la

\begin{abstract}
Blanca Lleó
Catedrática de Arquitectura en la Universidad Politécnica de Madrid, Académica de la Real Academia de Doctores de España, Visiting professor en Princeton Univ. y RISD (EEUU), Cambridge Univ (UK), Chinese Univ. Hong Kong y UNC (Medellín). Premios. Premio tesis ARQUIA, Premio Extraordinario UPM, Premio Investigación BEAU 2016, Premio Honorifico Nan-CSCAE 2018, Premio Endesa Arquitectura sostenible, Premio Ayuntamiento Madrid, Premio COAM, Finalista Premios FAD, Seleccionada Premio Europeo Mies van der Rohe. Concursos Nacionales (1er Premio): Centro Románico La Rioja, Faro Nules, Parque Salinas Cádiz, Ayuntamiento Lorca, Edificio Mirador y Edificio Celosía (coautoría Mvrdv), Edificio Mare Deu Barcelona. E-Mail: contacto@blancalleo.com
\end{abstract}


Fig. 02

Fábrica Steiff. Panorámica del conjunto con ampliaciones hacia 1910.

Fig. 03

Fábrica Steiff. Plano de licencia firmado y sellado. 1902. diosa del amor en el renacimiento, una imagen cuidadosamente seleccionada de la fábrica Fagus representó durante décadas con poderosa fuerza simbólica aquel momento primigenio de la nueva arquitectura. Este artículo trata de un edificio prácticamente desconocido que siendo anterior a la Fagus abre una nueva perspectiva para repensar la arquitectura emergente del siglo XX. Se trata de la fábrica Steiff, una obra insólita de extrema pureza y admirable significado social, una creación visionaria, concebida y ejecutada en 1903, que incorpora innovaciones arquitectónicas excepcionales. Esta construcción, ajena a los episodios destacados por la genealogía oficial del movimiento moderno, fue la primera caja de cristal habitada por trabajadores manuales en su quehacer diario. Lo que resulta verdaderamente sorprendente es que esta arquitectura haya pasado desapercibida e ignorada por historiadores y críticos a lo largo de todo el siglo $\mathrm{XX}^{2}$, o es que tal vez ha sido intencionadamente silenciada.

Las primeras noticias sobre esta factoría no aparecen hasta finales del siglo pasado e inicios del XXI en breves citas y en un par de artículos de carácter eminentemente técnico que hacen referencia a ella para destacar sus fachadas como el primer muro cortina de la historia ${ }^{3}$. Incidiendo en el aspecto constructivo, merecen especial mención los trabajos publicados en alemán de Anke Fissabre y Bernhard Neitha$\mathrm{mmer}^{4}$. En el ámbito anglosajón, un texto reciente en ingles de carácter histórico relaciona la fábrica Steiff con diversas construcciones anteriores y coetáneas 5 .

Consideramos que las citadas aproximaciones a los aspectos técnicos e históricos de la obra son insuficientes, pues para entender el verdadero alcance de la fábrica Steiff es imprescindible realizar un análisis arquitectónico completo y minucioso al tiempo que es perentorio poner de manifiesto la significativa trayectoria de su artífice Margarete Steiff. A continuación, se abordarán ambas cuestiones poniendo en evidencia el carácter paradigmático de esta obra en su contexto histórico y desvelando su significado como plasmación de las ideas de una industrial emprendedora y diseñadora pionera.

En el año 1903, el inesperado y fulgurante éxito de la marca Steiff llevó a su propietaria a levantar, en pocos meses, un nuevo edificio de tres plantas. La radical modernidad de la arquitectura de esta nueva factoría debió parecer algo insólito en Giengen, una urbe medieval situada a $80 \mathrm{~km}$ de Stuttgart, alejada, por tanto, de los circuitos de la cultura y la industria de vanguardia alemana de su tiempo. En los documentos históricos, se ve que las calles y plazas de esta pequeña ciudad de provincias componían un paisaje secularmente inmutable de construcciones tradicionales.

En una fotografía de la época -donde también se distinguen, en segundo plano, las sucesivas ampliaciones de 1904 y 1908-, podemos apreciar el radical contraste entre la arquitectura tradicional del pabellón de acceso y la nueva construcción de vidrio, objetivo principal de este trabajo. Situados ambos en el acceso a la factoría y enfrentados a la ciudad histórica, los dos edificios escenifican el signo de los tiempos en un inicio de siglo marcado por grandes cambios (fig. 02).

En la parte inferior del plano de situación original de la fábrica (fig. 03), fechado el 20 de febrero de 1903, se puede ver estampada una única firma bajo el sello de la licencia: es la rúbrica de Margarete Steiff -Die Bau Unternchmerin-6, cuya determinación y liderazgo permi- 


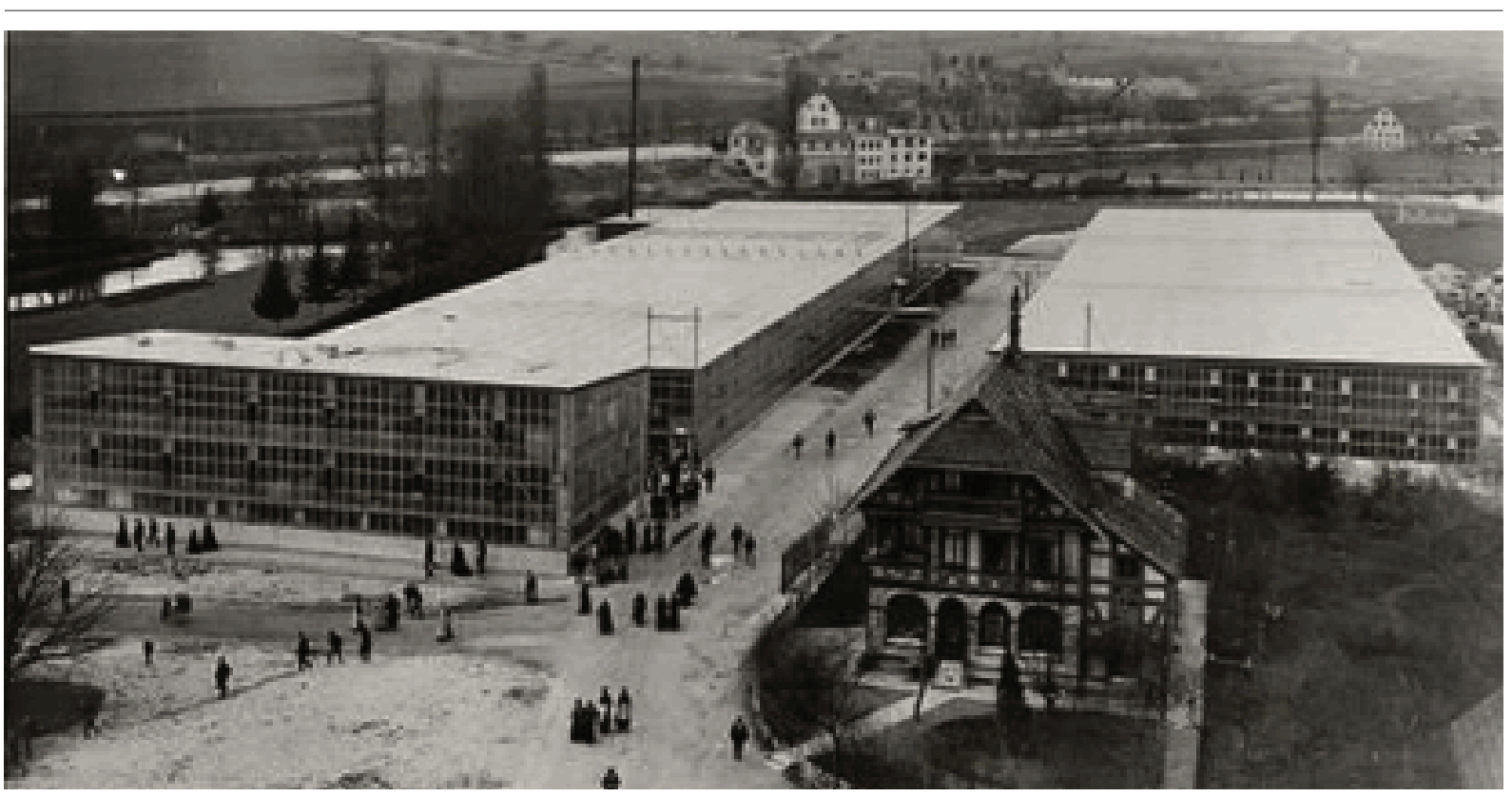

02

tieron superar todas las trabas impuestas por los inspectores de edificación a una arquitectura tan radicalmente novedosa como esta. ¿Quién es la persona que tuvo esta iniciativa y firma el documento?

Margarete Steiff nace en 1847 en Giengen an der Brenz, una población del sur de Alemania, situada en el límite de Bavaria. Su trayectoria, como empresaria creativa y renovadora social, goza de reconocimiento y se estudia en la actualidad en las escuelas de negocios por haber revolucionado el mundo del juguete y el coleccionismo con un proyecto personal que iniciado en las ultimas décadas del siglo XIX sigue siendo referente mundial tras mas de 125 años. Sin embargo, la singular arquitectura en la que dicho proyecto se sustentó -siendo una parte importante de su ambiciosa creación- no ha sido hasta hoy debidamente estudiada.

La joven alemana inicia su aventura empresarial alrededor de 1877 con el diseño de un pequeño elefante realizado con fieltros de colores cosidos a mano. En este simple objeto, concebido como alfiletero para las costureras, los niños van a descubrir de manera espontánea un nuevo juguete cargado de inesperadas sensaciones. La curiosidad y emoción que despierta el exótico y tierno animal conducirá a su éxito inmediato, y en muy poco tiempo la autora vende 5.170 unidades.

Así, de forma casi casual, comienza un proyecto empresarial de gran envergadura. Margarete ha inventado el muñeco de peluche, algo aparentemente banal que, no obstante, es sintomático del enorme cambio que se esta produciendo en la sociedad decimonónica en relación a la infancia, y es que se empieza a comprender que los más pequeños no son mano de obra barata, sino ciudadanos del futuro, y como tales deben ser cuidados y educados. La consideración de la niñez es algo nuevo, como señala George Steiner: "en el arte medieval y renacentista los niños pequeños eran adultos diminutos [...]. El niño es un descubrimiento de los siglos XVIII y XIX; lo 'inventaron' la sensibilidad romántica y las teorías rousseaunianas de la educación"?. La máxima en

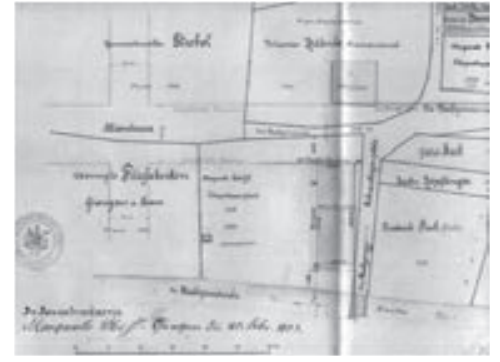

03 

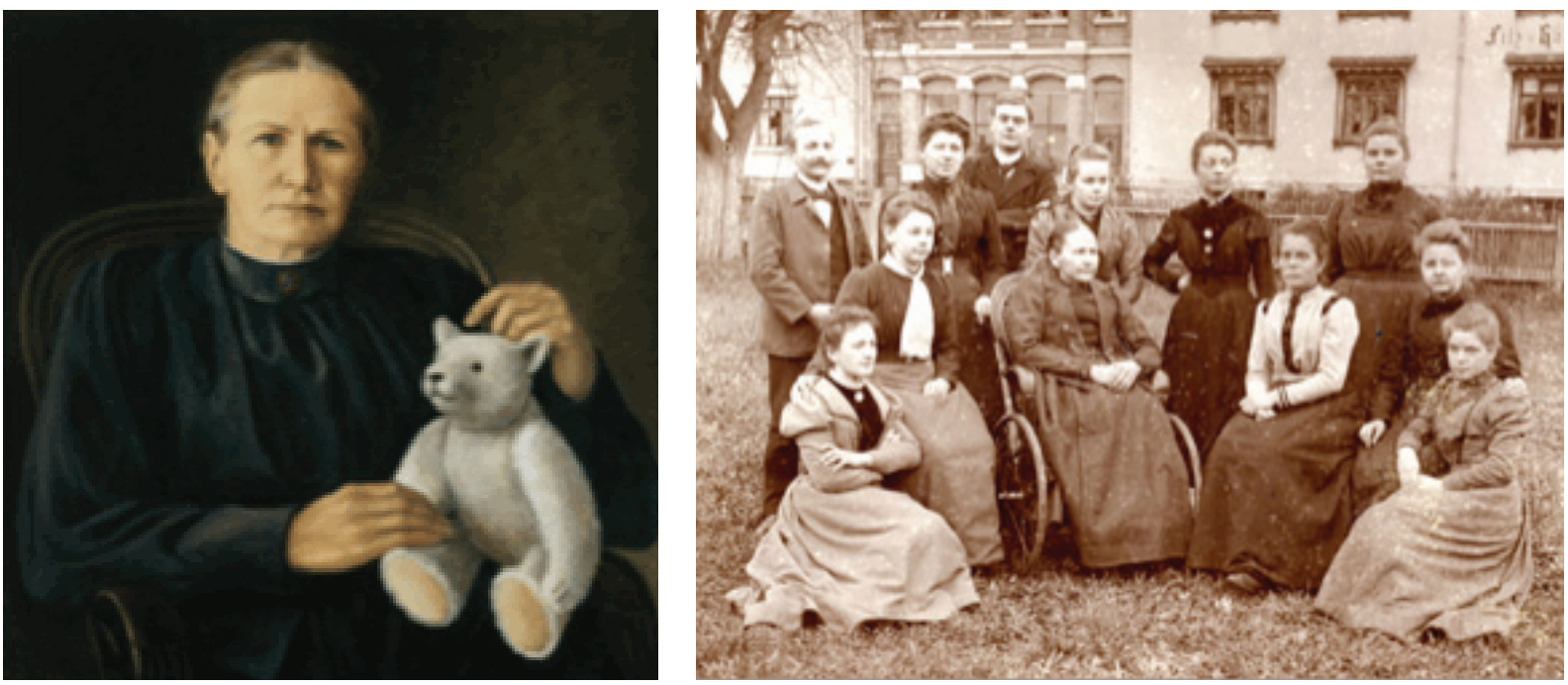

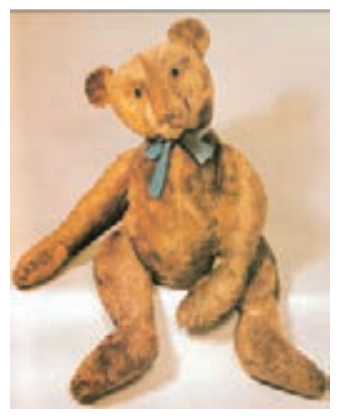

06

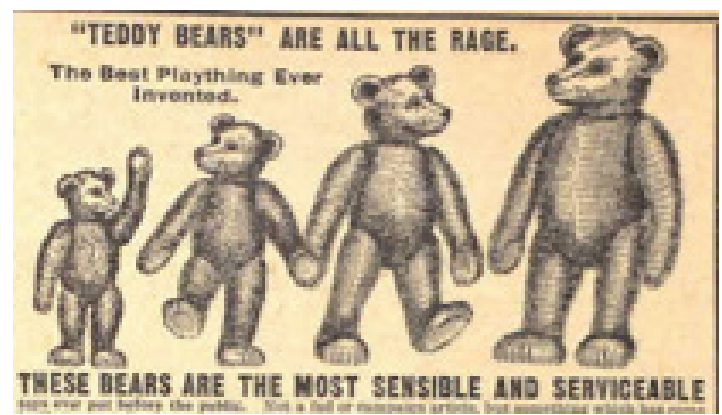

07
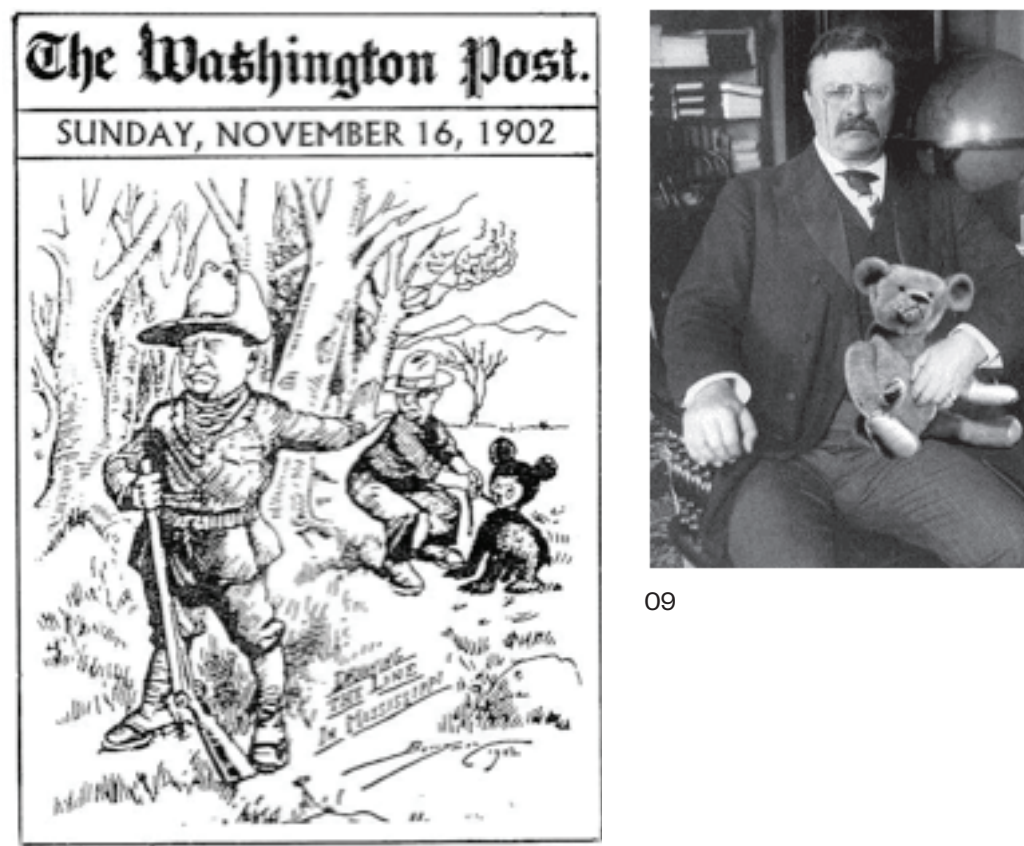

09 
que se apoyará todo el proyecto empresarial de Margarete Steiff es "los niños se merecen todo lo mejor", y sus diseños evindencian este incipiente cambio de mentalidad: los fríos soldaditos de plomo y las distantes muñecas de porcelana van a dar paso a tiernos peluches, portadores de calor y fantasía.

Tras aquel primer elefante de juguete y ya instalada, desde 1888 en su primer taller, van a surgir de la imaginación y las manos de Margarete muchos más animales: el tigre, el cerdo, el camello, el perro, el burro y el oso, entre otros (figs. 04 y 05).

Cuatro años más tarde, en 1892, en su afán por ampliar su ya creciente empresa, decide editar un primer catálogo. En él, se oferta el extenso repertorio zoológico creado hasta el momento y se incluye su famoso osito en cuatro colores y dos tamaños. Al año siguiente, animada por el empuje del proyecto, acude con sus productos a la Feria de Leipzig y, el 3 de marzo de 1893, registra su compañía, la Filzwarenfabrik Giengen/Brenz. Por entonces, cuenta ya con catorce empleadas, de las cuales cuatro trabajaban en la fábrica y diez lo hacen desde sus casas, conciliando el empleo con la vida familiar.

En los años siguientes, Margarete Steiff establecerá los primeros contactos en el extranjero, empezando por los grandes almacenes Harrods de Londres, donde, ya en 1895, se venden sus animales de peluche.

Será en 1902 cuando una extraordinaria confluencia de circunstancias proporcione un nuevo impulso a la compañía que desembocará en la creación del proyecto arquitectónico de la fábrica Steiff. En esta historia un episodio intrascendente será determinante, y es el viaje a Europa de Hermann Berg, un avezado comerciante de juguetes en busca de novedades. Recorriendo la feria de Leipzig, este americano -hermano del compositor Alban Berg- descubrirá de forma casual, en un pequeño estand, el producto más reciente de los Steiff, el oso de peluche articulado. Con una certera intuición, decide comprar 3.000 unidades del novedoso muñeco con el fin de introducirlo en los EE UU (figs. 06 y 07).

Casi al mismo tiempo, al otro lado del Atlántico, va a producirse un episodio memorable que van a reseñar todos los medios, en reportajes, viñetas y caricaturas. El presidente Theodore Roosevelt, consumado cazador, acaba de tener un gesto magnánimo y honorable, una acción que tendrá un fuerte significado en medio de las marcadas tensiones sociales que vive el país: en una cacería organizada en el estado de Mississippi, el mandatario perdona la vida a un desvalido osezno que se le ofrecía como trofeo de caza (fig. 08).

El osito Steiff aparecerá justo en el momento oportuno en el lugar adecuado, y la asociación simbólica entre el presidente americano y el oso de peluche perdurará hasta el día de hoy (fig. 09).

La feliz coincidencia convierte súbitamente el juguete de Margarete -que acaba de desembarcar en el nuevo continente- en un emblema nacional que será bautizado como Teddy Bear en recuerdo de la hazaña del presidente. A partir de entonces, se dispara la demanda en los Estados Unidos de América, haciéndose imprescindible incrementar en tiempo record el espacio productivo de la fábrica en Alemania.

Hace ya más de cien años que Teddy Bear se hizo famoso y hoy sigue siendo objeto de coleccionistas. Transcurridas seis generaciones, se mantiene en plena producción la empresa familiar creada por la matriarca Steiff en 1893, y el edificio original de 1903 sigue en uso como espacio de trabajo.
Fig. 04

Margarete Steiff y Teddy Bear. Pintura anónima.

Fig. 05

Margarete Steiff y sus empleadas en 1888 frente a su primer taller ejecutado al modo tradicional por su hermano Fritz, constructor como su padre.

Fig. 06

Teddy Bear hacia 1903.

Fig. 07

Teddy bear en todos los tamaños. El mejor juguete jamás inventado. Estos osos son lo mas sensible y servicial.

Fig. 08

Theodore Roosevelt, viñeta de su honorable hazaña. The Washington Post, 1902.

Fig. 09

Theodore Roosevelt y Teddy Bear. Fotomontaje. 
Para situar esta obra en el contexto de la historia de la arquitectura -en la que, como ya se ha dicho, no aparece ni siquiera mencionada-, conviene recordar que desde 1900 Alemania se halla en el centro de la cultura arquitectónica europea y que un factor determinante en la generación del movimiento moderno será la fundación en 1907 del Werkbund cuya finalidad es ennoblecer el trabajo artesano relacionándolo con el arte y con la industria. Es evidente que la gestación de la fabrica Steiff en 1903 se adelanta con espíritu visionario a los acontecimientos destacados por la historiografía, estando la obra por añadidura situada fuera de un entorno propicio por fecha y lugar. En contraposición la faguswerk de W. Gropius y A. Meyer será oportunamente consagrada por la ortodoxia como obra germinal del proyecto moderno.

Los primeros textos de la historia del movimiento moderno en arquitectura no aparecen hasta la década de 1930. Será entonces cuando los importantes textos de Nikolaus Pevsner y Sigfried Giedion ${ }^{8}$ elaboren una genealogía y establezcan la ya legendaria esquina de cristal de la Fagus-Werk, construida entre 1911 y 1913, como su indiscutible punto de partida. En las dos décadas que transcurren entre la realización de la obra y el relato historiográfico, la Fagus se consolida como obra canónica indiscutible; atribución que se perpetuará otros veinte años más, hasta que, tras el periodo bélico, se produzcan las primeras revisiones críticas, en el marco de un encendido debate arquitectónico que pondrá en cuestión el valor simbólico de la famosa esquina?.

El arquitecto e historiador italiano Bruno Zevi será de los primeros en hacerlo. En las páginas ilustradas de su Poética de la arquitectura neoplástica, de 1953, publica, junto a las fotos habituales de la Fagus, otras imágenes hostiles, que muestran la cara más dubitativa y clasizante de la obra de Gropius. De este modo, Zevi pone de manifiesto la perspectiva parcial y sesgada de la historiografía, al tiempo que pone en duda la veracidad de los valores modernos del feliz escorzo al señalar que ciertas vistas de la fábrica Fagus denotan "algunas persistencias tradicionales y un dibujo falto de soltura. Quien juzga las arquitecturas en su complejidad y no a través de pocas fotos, se dará cuenta de las inseguridades en los engastes de volúmenes, de la anomalía de una caja mural pegada al vítreo laboratorio por medio de un traspaso tan torpe que ni las decorativas incisiones horizontales logran esconderlo, de una escritura narrativa, epígono de las Arts and Crafts y del Art Nouveau [...]. El basamento de la Fábrica es decididamente antirracionalista: quiebra la unidad de la pared, fuerza un orden horizontal y lo vuelve pesado con cornisas, molduras y con un estridente portal"10.

La última página de este libro que tanta polémica levantó en su momento es especialmente incisiva. En ella se recogen veintiuna imágenes de esquinas de otras tantas arquitecturas emblemáticas. La secuencia empieza con el Templo de la Concordia de Agrigento, del siglo $\mathrm{V}$ a. C., y finaliza con la estación de Roma de 1951. Entre ambas, discurren vistas de esquinas del Duomo de Milán, el Palazzo Vecchio de Florencia, la Ca' d'Oro en Venezia, el Palacio Ducal de Urbino, el Palacio Strozzi en Florencia, Santa Maria della Pace de Bramante, además de obras de Auguste Perret, Josef Hoffmann, Erich Mendelsohn, Willem Marinus Dudok, William Lescaze, Le Corbusier y Giovanni Michelucci". En esa sucesión de encuadres fotográficos centrados en los diedros de las fachadas, resulta especialmente elocuente y significativa la omisión de la esquina de la Fagus.

Como es bien sabido, en 1960 el arquitecto e historiador británico Reyner Banham cuestiona abiertamente la obra de Gropius 
como dogma de la modernidad, al desenmascarar las visiones parciales e incluso tendenciosas de aquellos primeros historiadores germanófilos del movimiento moderno. Banham no tendrá reparos en utilizar expresiones como "trapos sucios" y "zonas de silencio" al referir el modo en que aquellos testigos de excepción establecieron el nacimiento y la genealogía de la arquitectura moderna ${ }^{12}$.

En la década de 1970, otros críticos desvelarán nuevas interpretaciones, entre las que destacan las perspicaces indagaciones y fructíferas incertidumbres que respecto a los inicios de la arquitectura moderna introduce Manfredo Tafuri. Por entonces, la argumentación sobre la veracidad o falsedad de la mítica foto de la Fagus ha perdido relevancia frente a la discusión en torno a la vigencia del proyecto moderno, sentenciado a muerte por algunos que como Tafuri buscaban "demostrar su complejidad y su fragmentariedad" al tiempo que se planteaban como objetivo "descubrir sus carencias, contradicciones, objetivos traicionados, errores"13, pues, como reitera el incisivo historiador italiano, "si la crítica no procediera así, seguiría colaborando en la formación de mitos que si bien eran precisos [en otros tiempos] -como fuerzas necesarias e indispensables para forzar la situación- ahora han de eliminarse"14.

Al hilo del discurso de Tafuri, el objetivo de este artículo es desvelar una de esas carencias y solventar un error rescatando del olvido la Steiff Factory de 1903, una arquitectura pionera que deviene en auténtico manifiesto moderno.

La puesta en marcha del nuevo espacio de producción Steiff en Giengen, va a ser tan frenética como el fulgurante éxito de su juguete mas famoso, el oso de peluche Teddy Bear. El resultado será una arquitectura innovadora y radical tan moderna como el modo y los tiempos de producción en que se lleva a cabo.

Es importante recordar que hasta ese momento y durante décadas Margarete Steiff ha gestado cuidadosamente un proyecto emprendedor de marcado carácter social enfocado hacia el bienestar de los niños y las mujeres trabajadoras. Su perseverancia, creatividad innovadora y visión social revolucionaria adquieren finalmente forma en una construcción cuya expresión simbólica del funcionalismo humanista será el sueño moderno perseguido por los arquitectos en las décadas venideras.

La fábrica Steiff es una arquitectura sin arquitecto, nada excepcional en los inicios del siglo XX cuando se producían habituales aportaciones de industriales, ingenieros y artistas a la nueva arquitectura. Tiempos de cambio en los que grandes maestros como Mies van der Rohe, Le Corbusier y Walter Gropius nunca llegaron a completar estudios oficiales ni obtuvieron un título académico de arquitecto al considerar obsoleta e inútil la formación decimonónica imperante.

La obtención de la licencia para la construcción en 1903 no fue tarea fácil pues los técnicos aventuraban que quien trabajara en un edificio completamente acristalado como era la fábrica Steiff, se expondría a perder la vista. Finalmente, el ministerio de comercio e industria del Württembergian y las autoridades locales descargaron su responsabilidad en la empresaria y concedieron los permisos.

Resultó tan efectiva la insólita solución de fachada que, en la misma década, cuando se hizo necesaria la construcción de dos nuevos edificios mucho más grandes, se recurrió al mismo sistema de cerramiento vítreo, si bien con estructura de madera en lugar de acero. 
Fig. 10

Fábrica Steiff. Planta tipo. 1902.

Fig. 11

Fábrica Steiff. Ejecución de estructura en perfiles de acero laminado. 1903.

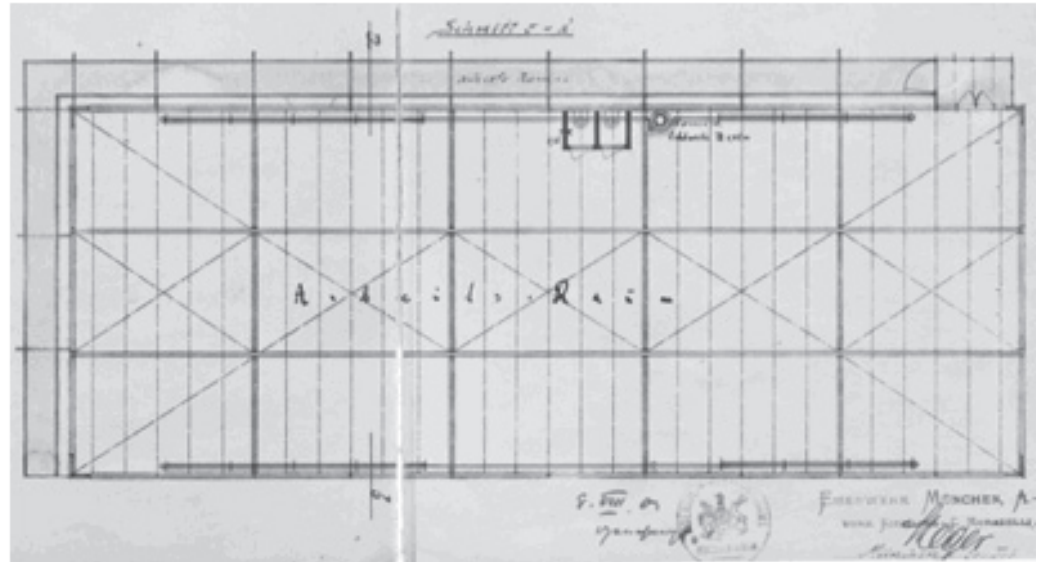

10

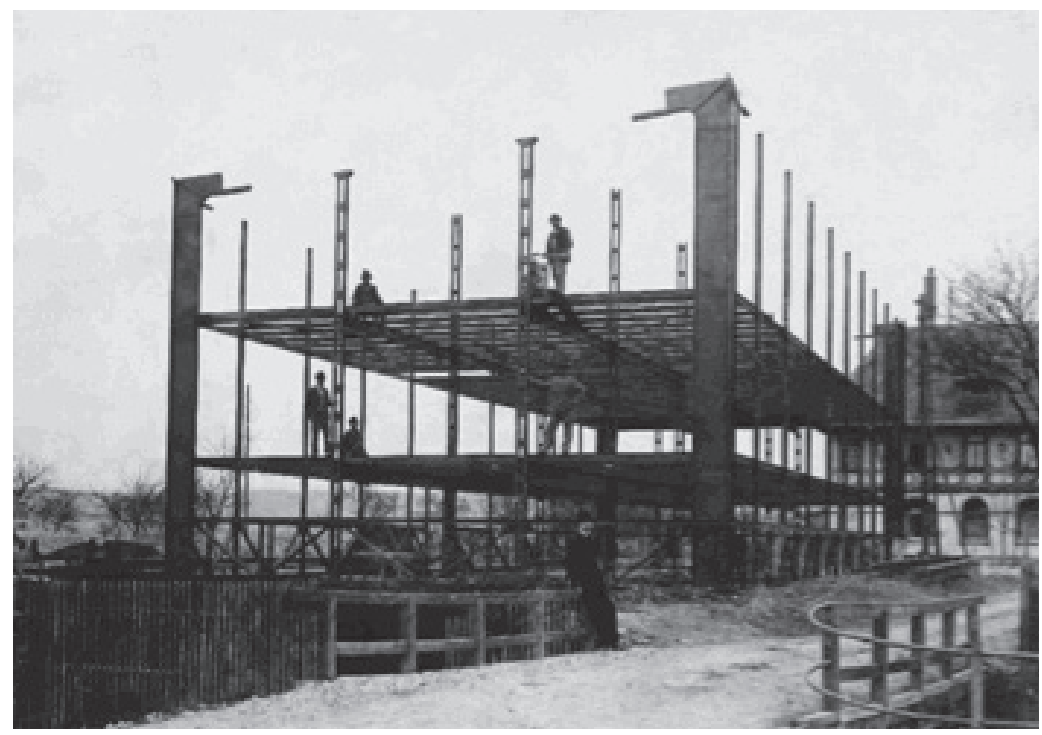

11

Hoy se puede afirmar sin paliativos que, en la fábrica Steiff, se llevó a cabo, en 1903, el primer muro cortina de la historia, con quince años de antelación respecto al Hallidie Building de San Francisco, generalmente reconocido como el muro cortina más antiguo de la historia ${ }^{15}$.

Esta investigación se centra en el primer volumen construido en el complejo Steiff, denominado bloque oriental, un rotundo prisma de tres pisos, 12,00 × 30,00 m en planta y 9,40 m de altura. Su estructura metálica de pórticos de acero roblonado y arriostrados a viento fue creada por la Eisenwerk München AG, en colaboración con la familia Steiff, y representa la técnica estructural más avanzada de la industria alemana del momento

La planta está dividida en tres naves por medio de dos pórticos longitudinales. Cada uno comprende seis pilares formados por dos perfiles en $U$ empresillados. De este modo, cada nivel tiene una superficie diáfana de $360 \mathrm{~m}^{2}$, con la única presencia de ocho pilares esbeltos, pues los restantes cuatro quedan embebidos en las fachadas laterales (fig. 10). 
Las cuatro esquinas del edificio alojan pilares en L, reforzados con placas y angulares roblonados, mientras que, a lo largo de las dos fachadas de mayor longitud, se intercalan nueve perfiles en I. Todo este entramado de acero transmite hasta la cimentación las cargas de los forjados, constituidos también por elementos metálicos, ordenados en cinco vanos transversales.

Tanto las diagonales horizontales que atan los pilares como los tirantes oblicuos que se vislumbran tras los cristales garantizan la rigidez tridimensional y el arriostramiento a viento del conjunto (fig. 11).

El esqueleto, de acero prefabricado en su totalidad, se levantó en pocos días y garantizó una arquitectura ligera, resistente y precisa. Es importante señalar que, en 1903, la fabricación industrial de este material era de reciente implantación, en particular en el caso de los perfiles laminados estandarizados. Habida cuenta de la lejanía de Giengen respecto de los centros de producción, adquiere especial valor esta obra cuya arquitectura supuso entonces un alarde de tecnología de vanguardia.

¿Cómo fue posible que, en semejante lugar y de forma tan temprana, se procediera con un sistema constructivo tan avanzado?

El edificio es sin duda la plasmación de un espíritu renovador, no solo en el aspecto tecnológico sino también en el estético y social, pues la solución constructiva, la racionalidad y la abstracción de la forma responden con claridad al uso previsto y a las necesidades de sus ocupantes, y constituye por tanto una expresión sin precedentes de la auténtica funcionalidad moderna.

La voluntad de innovación que manifiesta la factoría Steiff había nacido varias décadas antes con la invención de un nuevo producto -el juguete de peluche- y con la visión premonitoria de su difusión en el por entonces incipiente mercado internacional de consumo masivo. Por eso resulta evidente que esta arquitectura simboliza, en los inicios del proyecto moderno, el afán de cambio y progreso que siempre caracterizó la trayectoria pionera de su artífice Margarete Steiff.

Se ha especulado acerca de la autoría del proyecto Steiff, insinuando e incluso afirmando que fue obra de los varones de la familia $y$, en concreto, de su sobrino Richard, que contaba tan solo tres años de edad en 1880, cuando Margarete funda la empresa Steiff, y quince cuando la emprendedora pionera ya vendía sus famosos osos de peluche por catálogo. A la luz de los datos resulta patente e innegable el liderazgo de esta mujer admirable en toda la creación de la industria Steiff, desde sus inicios, con el diseño y desarrollo de los productos, hasta la consecución de los modernos edificios construidos en 1903, 1904 y 1908.

En la segunda mitad del siglo XIX, son incontables los obstáculos a los que se enfrentaba una mujer con ambición emprendedora. Margarete, nacida en 1847, fue consciente de ello desde una edad muy temprana, por lo que creó, desde el inicio de su actividad, un entramado empresarial estratégico del que hizo participes a los que serían sus herederos. Los seis sobrinos Steiff se formarán a instancias de la matriarca para los distintos cometidos de la empresa, y será ella quien les asigne desde muy jóvenes, la responsabilidad de las diversas áreas de dirección, financiación, ventas, marketing, desarrollo y nuevos productos Steiff. En una divertida fotografía vemos a todos ellos -por supuesto con imponentes bigotes- encaramados sobre pequeños elefantes de juguete de diferentes tamaños (figs. 12 y 13). La imagen, por una parte, evidencia 
el valor simbólico de aquel legendario paquidermo de fieltro que en un lejano 1877 creara en solitario la joven Margarete, y por otra, es la clara expresión de un decidido plan de futuro sustentado en la familia y elaborado por la industrial mucho antes de que naciera esta nueva generación Steiff'it.

Las cuatro fachadas de la fábrica Steiff están totalmente recubiertas de cristal y, a diferencia de la fábrica Fagus, no puede encontrarse indicio alguno de elementos arquitectónicos pertenecientes a la tradición o al pasado que atenúen su radical y continua tersura. Ésta concisa caja de cristal -conocida en sus días como "el acuario de las vírgenes" por las jóvenes que se afanaban laboriosas en su interior- deslumbra aún hoy como símbolo precursor de una nueva era.

La piel del edificio está compuesta por dos láminas vítreas de $3 \mathrm{~mm}$ separadas por una cámara de $25 \mathrm{~cm}$ que aloja la estructura metálica. Los cristales de $60 \times 90 \mathrm{~cm}$ se sujetan con una retícula de finos perfiles metálicos en forma de T, de $25 \times 35 \mathrm{~mm}$. Una serie de flejes puntuales, atados a la estructura metálica, solventan la tensión provocada por el viento sobre los delicados lienzos de la fachada.

La lámina cristalina externa discurre continua desde la base del edificio hasta su coronación, mientras que la interna va desde la cara superior de un forjado hasta la inferior del siguiente. Vemos, por tanto, que, en el exterior, no se producen las habituales interrupciones del plano vítreo debidas a la estructura vertical o a la presencia de los forjados. Esta doble piel de vidrio con cámara constituye, como ya se ha dicho anteriormente y como refrendan varios estudios recientes sobre fachadas, el primer muro cortina de la historia (fig. 14).

Conviene recordar que, tanto en la fábrica de Turbinas AEG de 1909 del maestro Berhens como en el famoso edificio de la Fagus de Gropius de 1911, no solo se interrumpe el plano de cristal de fachada -que queda recercado y sustentado por la estructura portante del edificio-, sino que, además, en ambos casos, el cerramiento de cristal está constituido por una sola lámina. A pesar de no haber sido reconocida como tal durante todo el siglo XX, si nos ceñimos a los criterios de la historiografía más ortodoxa, resulta evidente que la fábrica Steiff de 1903 es la pionera y la más moderna de las tres factorías.

Este nuevo edificio que aparece en Geingen, casi de la noche a la mañana y en fecha tan temprana, es, además una arquitectura cristalina sin precedentes en tanto que aloja personas y no máquinas, un lugar para el bienestar de sus ocupantes, en su mayoría mujeres realizando una labor manual virtuosa.

La luminosidad es determinante para la buena visión de quienes realizan un trabajo artesanal tan minucioso como es el cosido y montaje manual, más aún cuando, a principios del siglo XX, la luz artificial era escasa y de muy baja calidad.

En el edificio, la luz diurna que atraviesa por completo las fachadas de cristal ilumina de forma uniforme la totalidad de la planta. En los primeros tiempos, antes de la instalación de cortinas para mitigar la radiación excesiva, los vidrios se encalaban en los meses estivales y, al llegar el otoño, éstos recuperaban su transparencia. La apariencia del edificio era cambiante según la época del año y la hora del día. Como apunta brillantemente Colin Rowe, "lo transparente deja de ser lo que es perfectamente claro para convertirse en lo claramente ambiguo"1. 
La ventilación cruzada se resuelve con ventanas-cajón practicables, insertadas en las cuatro fachadas, garantizando así la renovación del aire sin romper la estanqueidad ni alterar la capacidad aislante del muro cortina (fig. 15). Por otra parte, para asegurar la temperatura ideal en el interior, se dispone un novedoso sistema de calefacción con vapor a baja presión.

El cristal utilizado en las fachadas no es transparente sino traslúcido. Además de resultar más económicos, los cristales texturizados catedra/ de la fábrica Steiff dotan el interior de una luminosidad homogénea y sin fuertes contrastes, una luz difusa necesaria para la labor de precisión ejecutada por manos expertas como las que operan en este lugar. Margarete Steiff, que, desde 1880 creaba y realizaba junto a sus empleadas piezas únicas de gran calidad, era muy consciente de ello y, en esa elección, debió primar sin duda su voluntad de proporcionar las mejores condiciones de trabajo a sus empleados, tanto dentro como fuera de la compañía. "La transparencia puede ser una cualidad inherente a la sustancia, o puede ser una cualidad inherente a la organización"18. Otra explicación del uso de cristales traslúcidos podría ser la necesidad de protegerse de la mirada de la competencia, del mismo modo que la novedosa implantación del famoso botón en la oreja de los Teddy Bears -Knopf in Ohn, introducido por Franz, otro sobrino de Margarete- protegía la marca de falsificaciones.

Desde el exterior, el volumen irradia un efecto misterioso y sugerente: se vislumbran sombras en movimiento sin que se definan los objetos y las figuras que discurren tras la fachada (fig. 16).

El acceso a las dos plantas superiores del edificio se produce a través de una rampa que se despliega en el exterior como prolongación de las calles y caminos de este nuevo límite urbano. El plano inclinado abraza el edificio y ofrece un recorrido ascendente desde el que se tiene una visión en movimiento de los aledaños: la ciudad medieval, las vías férreas y el arroyo Brenz. Esta solución innovadora sustituye a la habitual escalera y facilita un movimiento fluido y sin barreras tanto para las mercancías como para las personas que trabajan en la factoría. Pero, sobre todo, la rampa solventó la accesibilidad a su artífice, postrada desde niña en una silla de ruedas a causa de una poliomelitis contraída a temprana edad. El recurso del plano inclinado resultó ventajoso, además, desde el punto de vista económico, pues, al ser un elemento externo al volumen no contabilizó a efectos de licencia de obras y permitió prescindir de la energía y los medios mecánicos para el desplazamiento de embalajes y productos (fig. 17).

Pero el verdadero hallazgo que resultó de este tipo de conexión perimetral externa fue la liberación de las superficies interiores, desplegadas en espacios totalmente isótropos. En la planta se produce así una claridad y continuidad absolutas, pues al suprimir escaleras, ascensores, huecos y particiones, se dispone por completo de toda la superficie sin ninguna restricción para su uso. En éste como en otros aspectos arquitectónicos, difícilmente encontramos antecedentes modernos de espacios laborales con el grado de funcionalidad, adecuación constructiva y calidad espacial que aporta la fábrica Steiff.

En el interior, las fotografías de época ponen de manifiesto cómo esta arquitectura promueve una organización laboral igualitaria en la que las empleadas, sin un orden jerárquico ni una asignación específica de los puestos de trabajo, se organizan en bandas corridas perpendicu- 


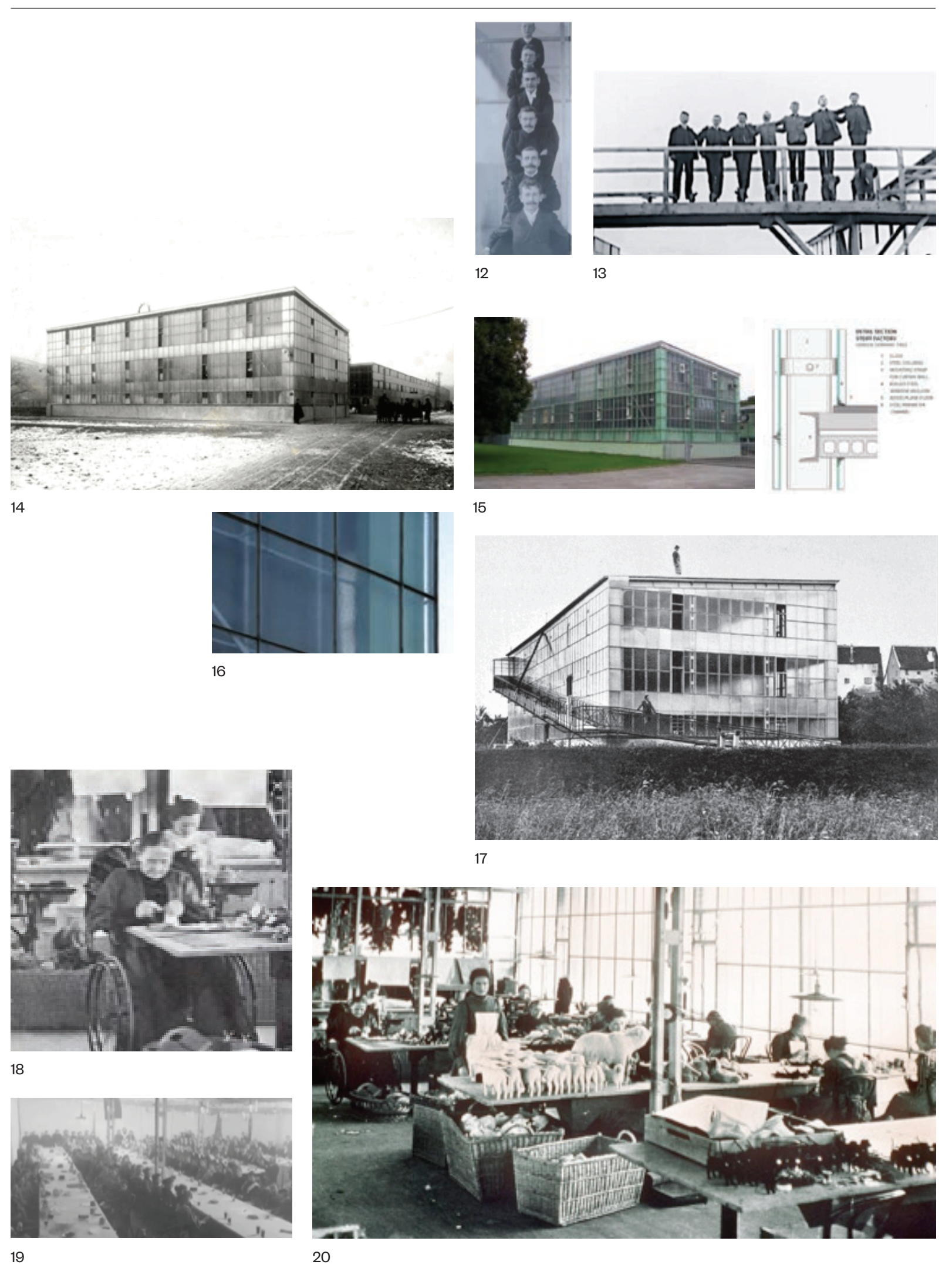


lares a la fachada. En la esquina de una de las largas mesas de madera podemos ver a Margarete en su silla de ruedas, cosiendo como una trabajadora más. Alrededor, se amontonan los juguetes de peluche a medio hacer o los ya terminados, en cestos y cajas. Las imágenes transmiten una organización cooperativa que también se manifiesta en las celebraciones de la empresa tal y como muestra otra foto antigua (figs. 18-20).

La ordenación libre del espacio, sin puestos de trabajo de emplazamiento fijo ni estructura por rangos -opuesta a la de las entonces habituales cadenas de montaje-, son conceptos muy avanzados para su tiempo, y se anticipan a un orden social y una organización laboral totalmente nuevos que no se implantará hasta muchas décadas después.

Desde el inicio de su actividad, Margarete Steif demostró ser una empresaria singular y ejemplar, siempre dispuesta a ingeniar fórmulas que permitiesen trabajar a las mujeres, al tiempo que soportaban toda la carga de las tareas domésticas y la crianza. Además, sus iniciativas fueron de una gran eficiencia, dando origen a un incremento espectacular de la producción en la fábrica. Por ejemplo, en el año 1904, se realizaron de forma artesanal 973.994 Teddy Bears además de dos millones de otros animales de peluche; con una calidad excepcional fueron ejecutados por una mano de obra compuesta por 400 empleados y empleadas que acudían a la factoría y 1.800 mujeres trabajadoras que, desde casa, compatibilizaban este trabajo con las exigencias de sus hogares ${ }^{19}$.

Reflejo de ese dinamismo es la rampa exterior, que se convierte en símbolo del crecimiento imparable de la firma. Esta poderosa diagonal que recorre la fachada -elemento al que recurrirán en décadas posteriores Le Corbusier, los constructivistas rusos y tanto otros- es todo un hallazgo en tanto que expresión plástica del movimiento continuo y de los acelerados cambios de los tiempos modernos, "cuando se hablaba sobre todo del veloz avance de la técnica, de globalización, de los progresos en el ámbito de la comunicación y de los cambios que afectaban al entramado social; entonces como ahora dejaba su sello en la época la cultura del consumo de masas; entonces como ahora, la sensación de vivir en un mundo en imparable aceleración, de estar lanzándose a lo desconocido, era arrolladora"20 (figs. 21 y 22).

El movimiento de personas y mercancías en constante circulación por este innovador plano inclinado que se encarama por las fachadas contribuye a una nueva percepción de la arquitectura, cambiante y abierta, que se manifiesta a través de su innovadora transparencia con la viva presencia de actores y objetos discurriendo por la rampa, un espacio intermedio entre el interior y el exterior de la factoría ${ }^{21}$.

Cuando, en 1909, muere Margarete Steiff a la edad de 62 años, la gran factoría de muñecos de peluche se ha completado con otras dos construcciones de mayor tamaño, que comparten con el primer volumen de 1903 el mismo sistema de fachada (fig. 23). Por entonces, la superficie totalmente acristalada con fachada de muro cortina suma un total de $15.000 \mathrm{~m}^{2}$.

Margaret nunca llegó conocer a Gropius -ni por supuesto la Fagus de Alfeld (1911-1913) de fecha posterior a su fallecimiento-, ya que ambos pertenecieron a épocas y entornos sociales totalmente alejados. Sin embargo, cabría aventurar que los pioneros de la arquitectura moderna en Alemania y en general aquellos vinculados a las vanguardias europeas, bien pudieron haber tenido noticia de la existencia del proyecto pionero de la empresaria e incluso haber visitado la fábrica de Margarete
Fig. 12

Sobrinos de Margarete Steiff, Paul, Richard, Franz, Hugo, Otto y Ernest.

Fig. 13

Los varones Steiff sobre elefantes, simbólica creación primera de Margarete.

Fig. 14

Fábrica Steiff. Giengen, Alemania. 1903.

Fig. 15

Fábrica Steiff. 1903. Detalle de esquina del volumen con cuatro fachadas de vidrio.

Fig. 16

Fábrica Steiff. Fachada de muro cortina con doble cristal translucido (catedral).

Fig. 17

Fábrica Steiff. 1903. Acceso por el exterior en rampa.

Fig. 18

Margarete Steiff en silla de ruedas trabajando en la ejecución de juguetes.

Fig. 19

Fábrica Steiff. Interior. Celebración de los trabajadores hacia 1903.

Fig. 20

Fábrica Steiff. Interior. En el ángulo izquierdo Margarete cosiendo. 


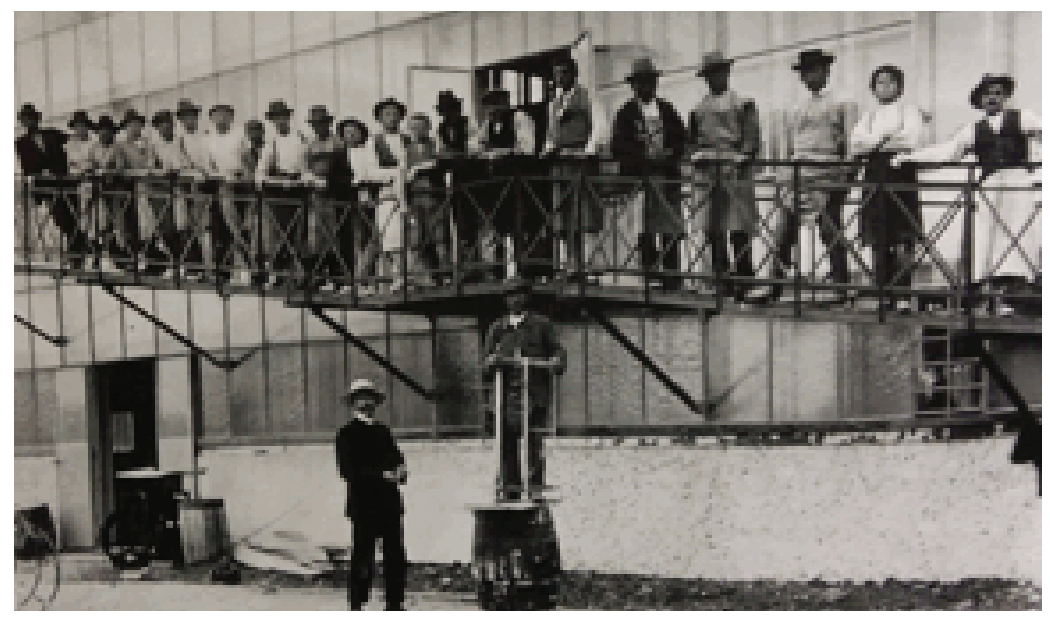

21

en Giengen, quedando sorprendidos por su radical pureza cristalina ${ }^{22}$. Lo más probable es que nunca lleguemos a averiguar si los historiadores y críticos más reconocidos de la modernidad centroeuropea supieron de la fábrica Steiff, lo cierto es que nunca dejaron constancia de ello.

La fábrica Steiff no existió para la historia de la arquitectura hasta finales del siglo $X X^{23}$, quedando relegada al ostracismo durante casi cien años. Por el contrario, la Fagus Werk, la mítica protagonista de la historia de la arquitectura, obtuvo un nuevo reconocimiento al quedar incorporada, en 2011, a la Lista del Patrimonio Mundial de la UNESCO, obviando las continuas dudas que han surgido a lo largo del tiempo respecto a sus valores ${ }^{24}$. A pesar de ello, puede afirmarse que los logros de la obra de Giengen suponen un paso que va más allá de lo que nunca llegó a completarse en el conjunto fabril de Alfeld o, dicho de otro modo, la fábrica Steiff, de 1903, es la consecución de unos ideales modernos que la Fagus, de 1911-1913, nunca alcanzó a materializar plenamente.

Este trabajo nos ha permitido constatar, una vez más, lo mucho que queda por descubrir en la arquitectura del siglo $X X$, un periodo extremadamente fértil e innovador de la historia de la arquitectura, tanto en lo que respecta a las ideas como a los proyectos y obras. Efectivamente, en el siglo pasado, y especialmente en las primeras décadas, se dieron infinidad de manifestaciones y cambios que influyeron de muy diversas maneras creando un inusitado caleidoscopio de aportaciones en la arquitectura y una enorme variedad de expresiones en la construcción, como nunca anteriormente se habían dado.

Dada la homogeneización generada por la globalización planetaria, es muy probable que esa diversidad no vuelva a producirse con igual esplendor. Sin embargo, confiamos en la creciente pluralidad de miradas capaces de sacar a la luz acontecimientos inéditos o autores y arquitecturas insólitas del pasado reciente tan ricas y elocuentes como la fábrica Steiff de 1903.

Nota: Todas las imágenes que han servido para ilustrar este artículo son accesibles y provienen de sitios de internet.
Desde la convicción de que solo vemos lo que podemos
pensar, hoy nos congratulamos del avance social y cultural que da cabida a lo diverso. Afirmamos el valor paradigmático de la Fabrica Steiff frente a la refrendada factoría Fagus, con la certeza de que lo contrario también es verdad pero eso ya lo dijo el poeta Hölderlin en $1795^{25}$. RA 


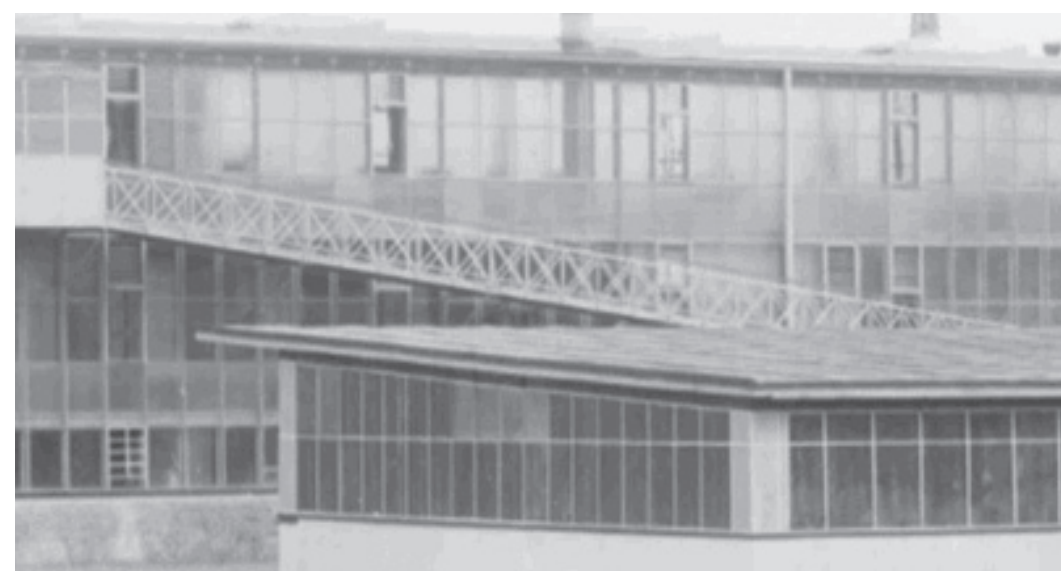

22
Fig. 21

Fábrica Steiff. Detalle del plano inclinado de la rampa de acceso.

Fig. 22

Fábrica Steiff. Posado de los trabajadores en la rampa de acceso al edificio.

Fig. 23

Fábrica Steiff. Vista desde la avenida entre las ampliaciones de 1904 y 1908. Al fondo en contraste con la arquitectura tradicional la pequeña ciudad de Giengen.

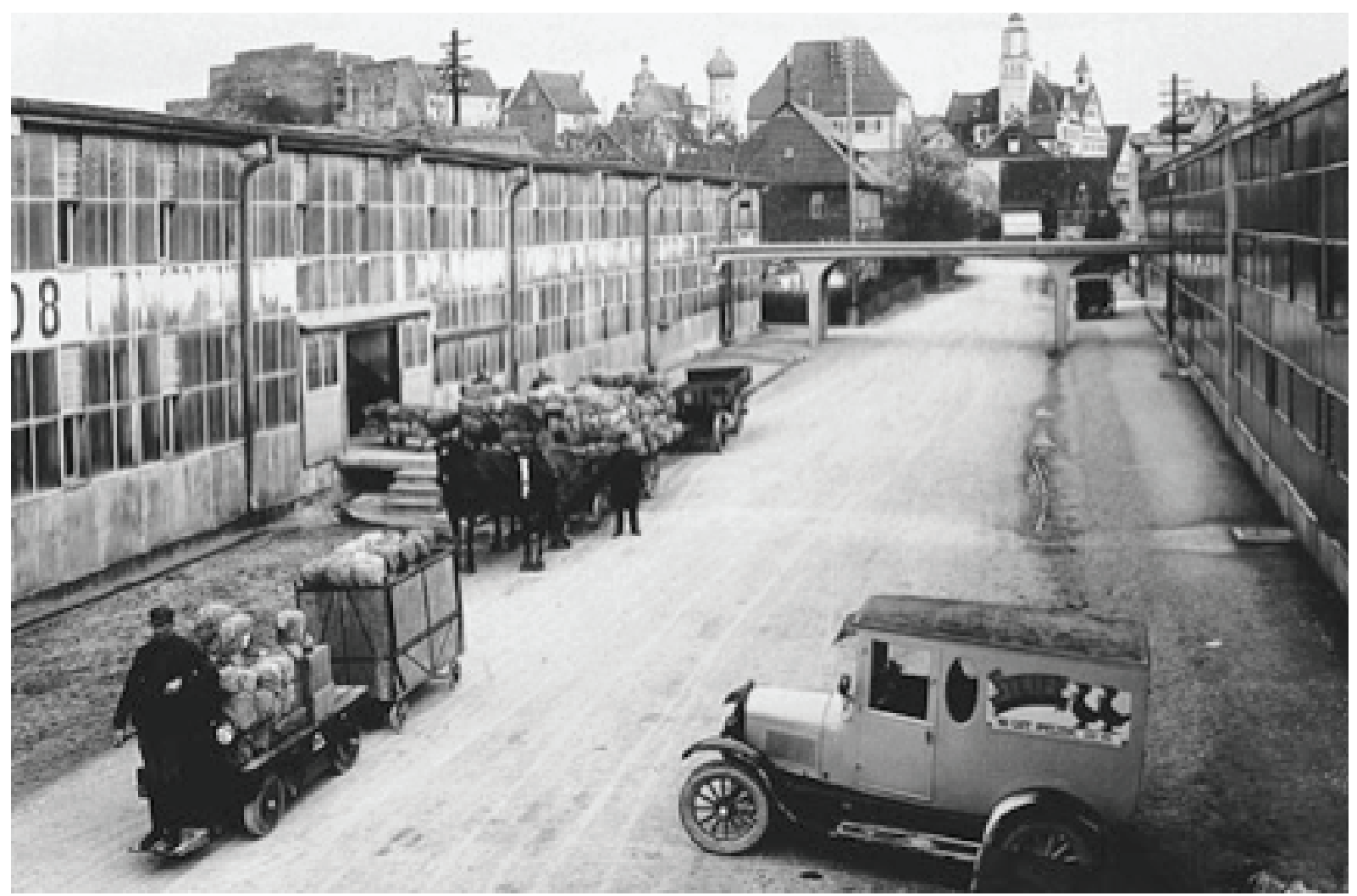


01. SMITHSON, Alison y Peter, "The Heroic Period of Modern Architecture", en Architectural Design, diciembre de 1965, p. 590 (reeditado en SMITHSON, Alison y Peter, "The Heroic Period of Modern Architecture Begins", en SMITHSON, Alison y Peter, The Heroic Period of Modern Architecture, Rizzoli International Publicatons Inc., Nueva York, 1981, p. 9). En la recopilación de obras que hacen Alison y Peter Smithson en este artículo, solo otros dos proyectos se muestran con la misma profusión de fotografías que la Fagus: la Villa Savoya de Le Corbusier y la Tugendhat de Mies. Con este repertorio de referencias, la nueva generación deja patente que, en la década de 1950, aún persiste la fe en el mito originario, según afirman en el mismo artículo, "El Periodo Heroico de la Arquitectura Moderna es la roca sobre la que nos apoyamos" (reeditado en SMITHSON, Alison y Peter, "Prelude to the Heroic Period of Modern Architecture", en SMITHSON, Alison y Peter, The Heroic Period of Modern Architecture, Ibídem, p. 5).

02. Para ser exactos, en 1932, se publican dos referencias en alemán: un breve artículo que trata casi exclusivamente de los difíciles trámites de la licencia y una nota a pie de página de un libro. Ambas son intranscendentes, aparecen citadas en el artículo de Robert y Brenda Vale.

03. ALBRECHT, Peter, "Fábrica Steiff, 1903. Steiff Factory", en a+t revista trimestral de arquitectura y tecnología, 11, VitoriaGasteiz, 1998; SCHITTICH, Christian (ed.), Building Skins, Detail/Birkhäuser, Múnich/Basilea, 2006; GÖSSEL, Peter (ed.), Arquitectura moderna de la A a la Z, 2 vol., Taschen, Colonia, 2007; MURRAY, Scott, Translucent Building Skins. Material Innovations in Modern and Contemporary Architecture, Taylor and Francis Group/ Routledge, Nueva York/Londres, 2013; FORTMEYER, Russell Martin, y LINN, Charles, Kinetic Architecture: Design for Active Envelopes. Images Publishing Group, Mulgrave, Vic, 2014.

04. FISSABRE, Anke, y NEITHAMMER, Bernhard, "The invention of Glazed Curtain Wall in 1903-The Steiff Toy Factory", en Third International Congress on Construction History Cottbus, en KURRER, Karl-Eugen, LORENZ, Werner, y WETZK, Volker, Brandenburg University of Technology, mayo de 2009, pp. 595-602.
En 2016, los mismos autores publicaron en alemán el libro Die Steiff Spie/warenfabrik in Giengen/Brenz, Geymüller, Verlag für Architektur, Aquisgrán, 2016.

05. VALE, Brenda, y VALE, Robert. "Gropius and the Teddy Bear: a tale of two factories", en Architectural Research Quarterly Journal, vol. 20, n. 4, diciembre de 2016. El artículo puede consultarse en https:// doi. org/10.1017/S1359135516000518 (publicado el 27 de abril de 2017, accedido el 12 de julio de 2019), pp. 345-356.

06. El empresario de la construcción.

07. STEINER, George, "De mortuis", en STEINER, George, George Steiner en The New Yorker [1981], Siruela, Madrid, 2009, p. 103.

08. PEVSNER, Nikolaus, Pioneers of the Modern Movement. From William Morris to Walter Gropius, Faber \& Faber, Londres, 1936, y GIEDION, Sigfried, Space, Time and Architecture. The growth of a New Tradition (The Charles Eliot Norton Lectures for 1938-39), Harvard University Press, Cambridge Mass, 1941.

\section{TOURNIKIOTIS, Panayotis, La} historiografía de la arquitectura moderna [1999], Reverté, Barcelona 2014. A lo largo de la historia de la arquitectura de la primera mitad del siglo XX, es evidente la influencia de Gropius sobre los historiadores y su papel dominante dado el enorme prestigio y capacidad de influencia que tenía como mediador entre instituciones y generaciones.

10. ZEVI, Bruno, Poética de la arquitectura neoplástica [1953], Victor Lerú, Buenos Aires, 1960, pp. 18-19.

\section{Ibídem, figuras 163 a 183}

12. "La faguswerke, de Alfeld que Gropius y Meyer comenzaron a proyectar en 1911, y cuya construcción duró hasta 1913, se considera con frecuencia como el primer edificio del Movimiento Moderno [...]. La modernidad [...] es visible, en efecto, sólo en las partes de los dos costados donde el taller mecánico y la central eléctrica presentan paredes vidriadas [...]. Dado el contraste tan marcado entre estos dos bloques y la convencional regularidad neoclásica de los demás edificios, cabría suponer que [... el parcial aspecto moderno] haya sido una consecuencia impensada [...] del programa funcional", en BANHAM, Reyner, Teoría y diseño en la primera era de la máquina [1960], Paidos Estética, Buenos Aires, 1985, p. 84. Banham lo expresa también en términos similares en "History and Psychiatry Archit", The Architectural Review, Londres, mayo de 1960.

13. TAFURI, Manfredo, Teorías e historia de la arquitectura. Hacia una concepción del espacio arquitectónico [1968], Laia, Barcelona, 1972, p. 12.

14. Ibídem, p. 11.

15. Véase notas 4 y 5 .

16. Richard Sennett analiza los grandes cambios en los sistemas de producción y en la demanda de la mercancía que se estaban produciendo en la segunda mitad del siglo XIX, cuando las empresas aprendían el arte de la estabilidad que asegurara la longevidad de las compañías con el aumento de empleados, en SENNETT, Richard, La cultura del nuevo capitalismo, Anagrama, Barcelona, 2006, pp. 29 y ss. También comenta, con relación al proceso de formación, que "La palabra alemana Bildung designa un proceso de formación personal que, en la juventud de una persona, fija su comportamiento vital de por vida", en Ibídem, p. 23. Así fue la formación de toda la "camada" Steiff, programada cuidadosamente por Margarete. El modelo de organización militar prusiano se estaba implantando entonces en Alemania, "las grandes corporaciones operaban cada vez mas como ejércitos en los que cada uno tenía un lugar y cada lugar una función definida", en Ibídem, p. 26.

17. ROWE, Colin, Manierismo y arquitectura moderna y otros ensayos, Gustavo Gili Barcelona, 1978, p. 156.

18. Ibídem, p. 157.

19. VALE, Brenda, y VALE, Robert, op. cit., p. 346.

20. BLOM, Philipp, Años de vértigo. Cultura y cambio en Occidente 1900-1914, Anagrama, Barcelona, 2010 [ The Vertigo Years: Change and Culture in the West, 1900-1914, Basic Books, Nueva York, 2008]. 
21. Siete décadas más tarde, el edificio Pompidou utilizará esta estrategia a gran escala con sus famosas escaleras mecánicas que, repletas de visitantes y transeúntes, simbolizan una nueva cultura de masas: "la muchedumbre ornamento" como generadora de la fachada en permanente cambio.

22. Es bien sabido que tanto Gropius como Mies observaban las construcciones fabriles como referentes modernos. Sabemos de su interés por las impresionantes fábricas que desde 1909 realizó el alemán Albert Kahn al otro lado del Atlántico. En su primer viaje a los EE.UU, en 1928, Gropius las visitó, admiró y fotografió, y Mies conoció las estructuras de acero y cristal de su compatriota cuando, en la década de 1940, comenzó su andadura en el MIT de Chicago.

23. Peter Albrecht es el autor del primer $y$ único articulo publicado en español sobre la fábrica Steiff. Se trata de un breve texto bilingüe español-inglés que da a conocer y pone en valor este edificio, a través de una pormenorizada descripción técnica de su estructura y su fachada. Sin embargo, el autor incurre en un error significativo al señalar que Richard Steiff "uno de sus hijos [...] proyectó junto a su padre, según parece, la nueva nave industrial de 1903 y la ampliación de 1904". Podemos constatar desde el primer párrafo del texto, como la verdadera artífice del proyecto queda relegada a la nada: "En 1880 la costurera Margarete Steiff fundó una empresa para la producción artesanal de elefantes de fieltro destinados, en principio, a servir como almohadillas para clavar alfileres". Atribuye, en cambio, la autoría de todas las creaciones, incluido el innovador edificio, a los varones de la familia: padre, hermano y también hijos -que, por cierto, Margaret nunca tuvo-, en ALBRECHT, Peter, "Fábrica Steiff", A+T: revista trimestral de Arquitectura y Tecnología, 11, 1998, pp. 4-9.

24. La propia directora del archivo de la Bauhaus, Annemarie Jaeggi, ha expresado dudas al respecto. Esta prestigiosa autora se sumaba, en el libro que publicó sobre la Fagus en el año 2000, a la crítica de Banham y Zevi -que cumple ya más de medio siglo-, confirmando la sesgada apreciación de la obra difundida por la historiografía, por medio de fotografías tendenciosas. Annemarie señala en su texto el afán de Gropius por contravenir al maestro Berhens, incidiendo en la limitación de sus logros, así le transcribe: "Me fascinaba la idea de lograr con medios constructivos nuevos [...] una ligereza en contraste con la acentuación del peso de la tierra [...] tan significativo para los métodos constructivos antiguos". Jaeggi continúa observando como, a pesar de que Gropius había intentado encontrar "una solución radical sin compromiso", no pudo renunciar en su fachada de la Fagus al efecto de pilón de esquina macizo con la escalera de mampostería de ladrillo, en JAEGGI, Annemarie, Fagus-Industrial culture from Werkbund to Bauhaus, Princeton Architectural Press, Nueva York, 2000. p. 7. Véase también HENZE, Kathrin, Fagus. La historia de una fábrica [trabajo de curso de doctorado en la Universidad Politécnica de Madrid, 2005-2006], Arquitectos de Cádiz, edición no venal, numerada, Cádiz, 2006, p. 43.

25. HÖLDERLIN, Friedrich, Hiperión o el eremita en Grecia, Hiperión, Madrid, 1982, p. 30.
RA. Revista de Arquitectura Núm. 22 - 2020

P. $142-159$ 